\title{
Imaging resemblance but diagnostic disparity in cervix cancer: a rare case report
}

\author{
Namita Agrawal ${ }^{1 *}$, Tarun Kumar Jain ${ }^{2}$, Abhishek Charan ${ }^{3}$, Sanjay Sharma ${ }^{4}$, \\ Hemant Malhotra ${ }^{3}$, Nitin Khuteta ${ }^{4}$, Ajay Yadav ${ }^{3}$
}

\begin{abstract}
${ }^{1}$ Department of Gynecology, SDMH, Jaipur, Rajasthan, India
${ }^{2}$ Department of Nuclear Medicine, MGMCH, Jaipur, Rajasthan, India

${ }^{3}$ Department of Medical Oncology, MGMCH, Jaipur, Rajasthan, India

${ }^{4}$ Department of Surgical Oncology, MGMCH, Jaipur, Rajasthan, India
\end{abstract}

Received: 23 May 2020

Accepted: 30 June 2020

\author{
*Correspondence: \\ Dr. Namita Agrawal, \\ E-mail: namitaagarwalsms@gmail.com
}

Copyright: (C) the author(s), publisher and licensee Medip Academy. This is an open-access article distributed under the terms of the Creative Commons Attribution Non-Commercial License, which permits unrestricted non-commercial use, distribution, and reproduction in any medium, provided the original work is properly cited.

\begin{abstract}
F-18 FDG PET-CT is an establish modality for staging of cervical cancer. The high uptake value in PET with no evidence of necrosis in CECT is generally understood malignant pathology in known cancer patients. A 47 year-oldfemale with cervix carcinoma underwent staging FDG PET-CT. It showed FDG avid primary lesion in cervix with FDG avid pelvic, retroperitoneal, mediastinal and supraclavicular lymph nodes. USG guided FNA from the supraclavicular lymph node revealed tuberculosis. Now patient scheduled for ATT and chemotherapy.
\end{abstract}

Keywords: Cervix carcinoma, F-18 Fluorodeoxyglucose PET-CT, Metastatic carcinoma, Tuberculosis

\section{INTRODUCTION}

Uterine cervix cancer is fourth most frequently diagnosed malignancy and leading cause of cancer death in women. ${ }^{1}$ International Federation of Gynecology and Obstetrics (FIGO) has described cervical cancer staging from stage I, which is non-invasive, to stage IV, in which the carcinoma has extended beyond the true pelvis or has involved the mucosa of the bladder or rectum or spread to distant organ..$^{2,3}$ The diagnosed patients are treated with surgery, chemotherapy and radiotherapy either alone or by combination of the two options, according to stage of the disease. ${ }^{3}$

To assess the disease burden, non-invasive imaging modalities computed tomography (CT) and magnetic resonance imaging (MRI) have been employed. The major limitation of these modalities is their dependence on morphological size to diagnose pathology and the limited body region that is imaged. ${ }^{4}$ The whole body F-18 Fluoro-2-deoxyglucose (F18 FDG) positron emission tomography PET-CT is an imaging modality, which provides combined metabolic and anatomical information and now FDG PET-CT is an integral step for evaluation of patients with diagnosed and suspected malignancy. ${ }^{1,5}$ The present case highlights the limitation of the FDG PET-CT in staging.

\section{CASE REPORT}

A 47 year-old-female presented with history of intermittent bleed from vagina since 20 days. There was progressive weight loss and weakness for 3 months. There was no past history of previous surgery, tuberculosis, hepatitis, or any other chronic illness. On per vaginal examination, there was palpable swelling the vagina and cervix. USG abdomen-pelvis revealed mass in the cervix. USG guided biopsy from the cervix lesion revealed squamous cell carcinoma on histopathology. Before scheduling on treatment, whole body F-18 FDG PET-CT was performed for staging. FDG PET-CT showed FDG avid (SUVmax 19.3) heterogeneously 
enhancing soft tissue density mass $(\sim 6.0 \times 7.0 \times 9.9 \mathrm{~cm})$ in the cervix (Figure 1) and extending upward in uterine cavity and downward in lower $1 / 3$ of the vagina. There was significant parametrical extension of the lesion and abutting the bilateral pelvic ureters resultant bilateral hydroureteronephrosis.

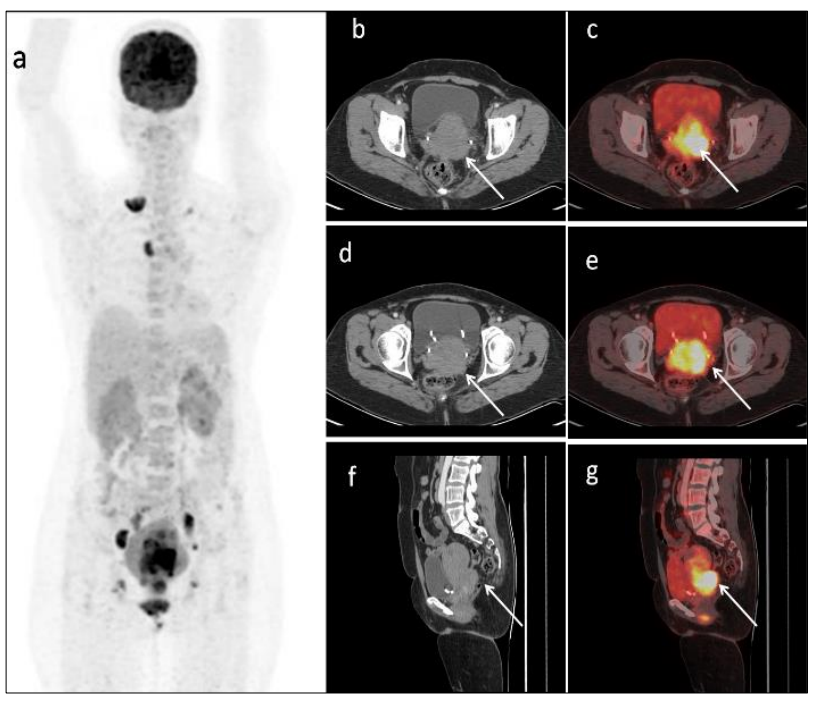

Figure 1: F-18 FDG PET-CT maximum intensity projection image (a) reveals few hot spots in bilateral supraclavicular, upper mediastinal and pelvic regions.

Corresponding transaxial and sagittal CECT and

fused PET-CT images of pelvis (Figure b-g) reveal

FDG avid (SUVmax 19.3) heterogeneously enhancing large soft tissue density mass $(\sim 6.0 \times 7.0 \times 9.9$ $\mathrm{cm})$ in the cervix and extending upward in the lower uterine segment and downward in the lower $1 / 3$ of the vagina. Note is made of catheterization of the bilateral ureters.

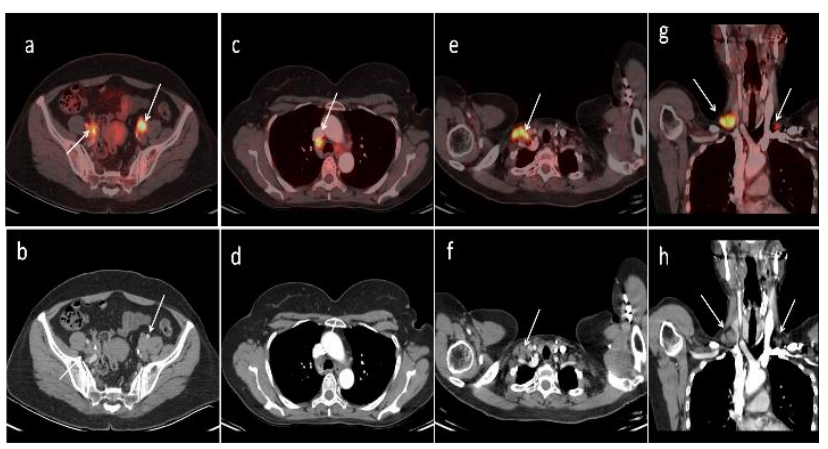

Figure 2: Corresponding trans-axial (Figure 2 a-d)

CECT and fused PET-CT images of pelvis and thoracic regions revealed FDG avid bilateral internal iliac (on right side SUVmax 11.7; $2.0 \times 2.2 \mathrm{~cm}$; arrow) and right lower paratracheal (SUVmax 9.3; 1.3×1.6 cm) lymph nodes are noted. Corresponding transaxial and coronal (Figure 2e-h) CECT and fused PET-

CT images of cervical and upper thoracic region revealed FDG avid bilateral supraclavicular (on right side SUVmax 12.6; $\sim 2.2 \times 1.1 \mathrm{~cm}$ ).

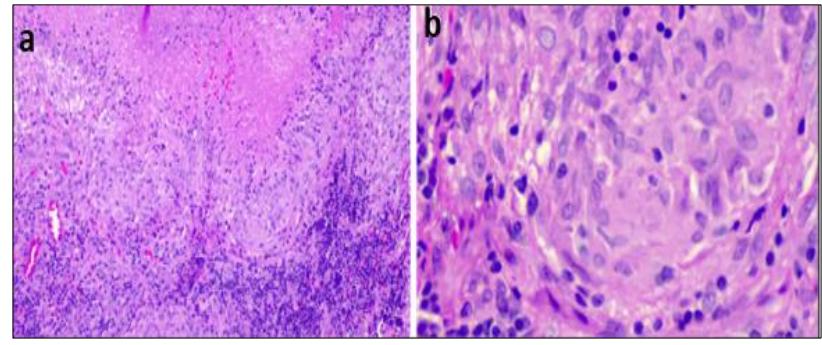

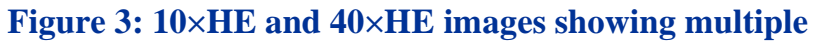
well defined and confluent epithelioid cell granulomas, Langshan's type of giant cells and focal area of necrosis.

Addition to the primary lesion in the cervix, FDG avid aortocaval (SUVmax $4.5 ; \sim 0.8 \times 0.9 \mathrm{~cm}$ ), paraaortic, bilateral common iliac, bilateral internal (on right side SUVmax 11.7; 2.0×2.2 cm), left external iliac, ,bilateral supraclavicular (on right side SUVmax 12.6; 2.2×1.1 $\mathrm{cm}$ ) and right lower paratracheal (SUVmax 9.3; 1.3×1.6 $\mathrm{cm}$ ) lymph nodes are also noted (Figure 2). Finally, authors have concluded FDG avid lesion in the cervix as known primary pathology and metastatic to pelvic, retroperitoneal, mediastinal and supraclavicular lymph nodes.

After PET-CT, patient underwent USG guided FNA from both sided of the supraclavicular revealed (Figure 3) multiple well defined necroting epithelioid cell granulomas with no evidence of malignancy s/o tuberculosis. Now Patient scheduled for ATT and chemotherapy.

\section{DISCUSSION}

FDG PET-CT is a routine prescribe investigation in cervical cancer patients before scheduling them for treatment. Any positive findings in form of focal tracer uptake on 18F-FDG PET were anatomically localized on contrast enhanced $\mathrm{CT}$ is interpreted as positive for disease. Lesions seen on PET/CT are grouped into local disease, nodal metastasis and distant metastasis. Maximum standardized uptake value (SUVmax) is used for the purpose of semi-quantitative analysis. ${ }^{6}$ The present case is showing both benign and malignant diseases are simultaneous coexisting in same patient at same sitting with high uptake values on FDG PET-CT. It is not easy to differentiate between benign and malignant pathology on FDG PET-CT when both shows high tracer uptake value in cancer patient and anatomically existing at possible metastatic site. The previous published literature has shown that high SUVmax on FDG PET-CT is highly suggestive for mitotic pathology in known cancer patient. ${ }^{7,8}$ In present case, SUVmax value of the left supraclavicular lymph node was 12.6; which was quite high of described cutoff limits in the published literature. However, this is known that FDG PET-CT can show FDG uptake in the benign tubercular pathologies but in present case it was difficult to decide whether 
intensely FDG avid supraclavicular lymph nodes can be tubercular on FDG PET-CT. ${ }^{9}$ So careful initial evaluation of these unusual issue on higher rank imaging modalities like FDG PET-CT, authors can offer improved management.

\section{CONCLUSION}

It is essential to give special care towards such sites and different nature of the of the lymph nodes in primary mitotic pathology. With proper initial evaluation of these unusual issue, we can provide better management

Funding: No funding sources Conflict of interest: None declared

Ethical approval: Not required

\section{REFERENCES}

1. Bray F, Ferlay J, Soerjomataram I, Siegel R, Torre LA, Jemal A. Global incidence statistics 2018: GLOBOCAN: estimates of incidence and mortality worldwide for 36 cancers in 185 countries. Cancer J Clin. 2018;68:394-424.

2. Bhatla N, Berek JS, Cuello Fredes M, Denny LA, Grenman S, Karunaratne K, et al. Revised FIGO staging for carcinoma of the cervix uteri. Int $\mathbf{J}$ Gynaecol Obstet. 2019;145:129-35.

3. Liu FY, Lai CH, Yang LY, Wang CC, Lin G, Chang CJ, et al. Utility of (18) F-FDG PET/CT in patients with advanced squamous cell carcinoma of the uterine cervix receiving concurrent chemoradiotherapy: a parallel study of a prospective randomized trial. Eur J Nucl Med Mol Imaging. 2016;43:1812-23.

4. Torizuka T, Nobezawa S, Kanno T, Futatsubashi M, Yoshikawa E, Okada $\mathrm{H}$, et al. Ovarian cancer recurrence: role of whole-body positron emission tomography using 2-[fluorine-18]-fluoro-2-deoxy-Dglucose. Eur J Nucl Med Mol Imaging. 2002;29:797803.

5. Kitajima K, Murakami K, Kaji Y, Sakamoto S, Sugimura K. Established, emerging and future applications of FDG-PET/CT in the uterine cancer. Clin Radiol. 2011;66:297-307.

6. Hofman MS, Hicks RJ. How we read oncologic FDG PET/CT. Cancer Imaging. 2016;16:35.

7. Choi J, Kim HJ, Jeong YH, Lee JH, Cho A, Yun M, et al. The role of (18) F-FDG PET/CT in assessing therapy response in cervix cancer after concurrent chemoradiation therapy. Nucl Med Mol Imaging. 2014;48:130-6.

8. Chung HH, Jo H, Kang WJ, Kim JW, Park NH, Song YS, et al. Clinical impact of integrated PET/CT on the management of suspected cervical cancer recurrence. Gynecol Oncol. 2007;104:529-34.

9. Jain TK. Tuberculosis presenting as cutaneous erythema nodosum on 18F-FDG PET/CT. Clin Nucl Med. 2019;44:e406-8.

Cite this article as: Agrawal N, Jain TK, Charan A, Sharma S, Malhotra H, Khuteta N, et al. Imaging resemblance but diagnostic disparity in cervix cancer: a rare case report. Int $\mathrm{J}$ Reprod Contracept Obstet Gynecol 2020;9:3480-2. 